\title{
Mobile Augmented Reality and Language-Related Episodes
}

\section{TETYANA SYDORENKO AND JOHN HELLERMANN}

Portland State University

Portland, Oregon, United States

\section{STEVEN L. THORNE}

Portland State University

Portland, Oregon, United States

University of Groningen

Groningen, Netherlands

\section{VANESSA HOWE}

Bilkent University

Ankara, Turkey

Applications of locative media (e.g., place-based mobile augmented reality $[\mathrm{AR}]$ ) are used in various educational content areas and have been shown to provide learners with valuable opportunities for investigation-based learning, location-situated social and collaborative interaction, and embodied experience of place (Squire, 2009; Thorne \& Hellermann, 2017; Zheng et al., 2018). Mobile locative media applications' value for language learning, however, remains underinvestigated. To address this lacuna, this study employed the widely used construct of language-related episodes (LREs; Swain \& Lapkin, 1998) as a unit of analysis to investigate language learning through participation in a mobile AR game. Analysis of videorecorded interactions of four mixed-proficiency groups of game players (two English language learners [ELLs] and one expert speaker of English [ESE] per group) indicates that LREs in this environment were focused on lexical items relevant to the AR tasks and physical locations. Informed by sociocultural theory and conversation analysis, the microgenesis of learners' understanding and subsequent use of certain lexical items are indicated in the findings. This understanding of new lexical items was frequently facilitated by ESEs' assistance and the surrounding physical environment. A strong goal orientation by both ESEs and ELLs was visible, providing implications for taskbased language teaching approaches.

doi: 10.1002/tesq.507 
L ocative media such as mobile devices and smartphones are rapidly becoming ubiquitous across much of the world (Dahlstrom, Brooks, Grajek, \& Reeves, 2015; Frith, 2015). It comes as no surprise that the prevalence of mobile devices is accompanied by the increasing popularity of mobile games and activities (McDonald, 2017). While digitally rendered persistent game worlds remain dominant in largescale commercial game development, technologies such as augmented reality and virtual reality are expected to "change how consumers communicate with each other and interact with content" (Global Games Market, 2016, para. 8). Portable locative media such as smartphones have opened up new possibilities for interfacing embodied and virtual experience. Of direct relevance to the research we present below, mobile game and social media researchers are exploring the potential of locative media to enable and enhance interaction among humans and the social spaces they inhabit, and in part produce, through the use of location-aware mobile devices (Saker \& Frith, 2018).

As has been the case since the widespread availability of personal computers and Internet connectivity, more recent technologies such as location-aware mobile devices (the iPhone debuted in 2007) are also likely to impact the way we use and teach language. In this article, we explore the use of mobile augmented reality (AR) as a catalyst for spatially contextualized language use and learning by drawing on sociocultural theories of development, language-related episodes (LREs) as a unit of analysis, sequential analysis afforded by ethnomethodological conversation analysis, and situated, multimodal analyses that attend to the significance of place.

Studies indicate that AR games and activities create opportunities for collaborative engagement and problem solving by providing location-specific information, virtual dialogue, prompts, and uses of media such as images and video (Hellermann, Thorne, \& Fodor; 2017; Holden \& Sykes, 2011; Perry, 2015; Thorne, Hellermann, Jones, \& Lester, 2015; Zheng et al., 2018). Although existing research has examined language learning in $\mathrm{AR}$ games from the eco-dialogical perspective (i.e., learning while doing and language as action in specific places; e.g., Zheng et al., $2018^{1}$; Zheng, Schmidt, Hu, Liu, \& Hsu, 2017), how game players explicitly orient to language has not yet been investigated (though this has been called for by some researchers, e.g., Sert \& Balaman, 2018). The analysis of interactional data in our current study is informed by a long trajectory of work pioneered by Merrill Swain and colleagues, particularly their insights and methodological contributions involving LREs, collaborative dialogue, and languaging. Building on a Vygotskian developmental

\footnotetext{
${ }^{1}$ Zheng et al. (2018) sought to "understand how space/place, technologies and people function together as a system for language learners to experience events" (p. 46).
} 
foundation that emphasizes the central importance of language for mediating individual cognition and group interaction, Swain began her work in this area by exploring the ways in which dialogue is used for knowledge building, problem solving, and decision making (among other functions), what she initially termed collaborative dialogue (Swain, 2000) and later languaging (Swain, 2006). As participants use language to externalize and share their ideas and opinions, utterances become objects (or artifacts) that can be assessed, agreed with or negated, and added to or contested in the ongoing flow of activity. In this way, participants coconstruct meanings and next actions, processes that have been linked to language development in contexts involving both learner-learner (see Swain \& Watanabe, 2013, for a review) and learner-expert speaker interactions (Fernández Dobao, 2012; Tocaimaza-Hatch, 2016).

In the present study, we focus specifically on LREs that are attested instances of meta-awareness of language form, function, and meaning, including self- and other-correction and explicit attention to any linguistic feature or communication problem arising in the interaction (Swain \& Lapkin, 2001). Using a database of videorecorded interactions, we investigate how LREs arise in the place-based context of an AR game. Second, we examine patterns of LREs in mixed groups of two English language learners (ELLs) and one expert speaker of English (ESE). The review of the literature first describes research on collaborative gaming, followed by use of LREs as an established unit of analysis from the perspective of sociocultural theory.

\section{Gaming, Interaction, and Language Learning}

In technology-assisted language learning, the concept of tasks has received central attention. In contemporary understanding of taskbased language teaching (TBLT), tasks should have a primary focus on meaning, orient learners to complete a goal, be learner-centered, be holistic (i.e., authentic and emulating real-world conditions), and include reflective learning (González-Lloret \& Ortega, 2014). Digital games, when designed to fit this conceptualization of a task, may provide useful environments for social interaction and language learning (Purushotma, Thorne, \& Wheatley, 2009; Reinhardt \& Thorne, 2016). Learner interaction during game play has been documented in virtual worlds ${ }^{2}$ such as Second Life (Zheng, 2012), simulation games ${ }^{3}$ such as The Sims (Purushotma, 2005; Ranalli, 2008), and massive multiplayer

\footnotetext{
${ }^{2} 3$-D environments in which users are able to create new objects and interact in the environment with other users via graphical representations of the user known as avatars (Berns, Gonzales-Pardo, \& Camacho, 2013).

${ }^{3}$ Simulation games are designed to simulate real-life activities within a $3-\mathrm{D}$ environment.
} 
online games ${ }^{4}$ (MMOGs) such as World of Warcraft (WoW; Newgarden \& Zheng, 2016; Rama, Black, Van Es, \& Warschauer, 2012; Scholz \& Schulze, 2017; Thorne, 2008, 2012b; Zheng, Newgarden, \& Young, 2012). Much of this research looks at text-based learner interactions and collaboration during game play. For example, Thorne (2008) described language learning opportunities within WoW in text-based conversation between two gamers, one from North America, the other from Ukraine. Both learners provided one another with explicit formfocused linguistic assistance and expert knowledge in their respective first languages (L1s). Several studies have examined players' spoken interactions, namely Piirainen-Marsh and Tainio (2009), Zheng et al. (2012), Newgarden, Zheng, and Liu (2015), Newgarden and Zheng (2016), and Reinders and Wattana (2014). Zheng et al. discovered that language was a central part of planning actions, coordinating group actions, reflecting on actions within the game scenarios, and negotiating meaning. Newgarden and Zheng likewise found that groups of learners and native speakers playing WoW together engaged in a wide range of communicative activities, broadly categorized as attending to others' needs, facilitating gameplay, and meaning making.

Although not as well documented, newer uses of locative technologies, such as AR, are being examined for their educational value and capacity to contextualize the learning experience with a deeper sense of place (Johnson et al., 2016). Unlike the better known immersive experience of virtual reality (Schwienhorst, 2002), a locative media AR approach juxtaposes or laminates mobile device-displayed information onto the perceptible physical world. Researchers have recently begun to explore uses of AR for pedagogical purposes, and our project has benefited from these earlier investigations (e.g., Hellermann et al., 2017; Holden, Dikkers, Martin, \& Litts, 2015; Liu \& Tsai, 2013; Squire, 2009; Thorne et al., 2015; Zheng et al., 2018; also see Godwin-Jones, 2016, for a recent review) ${ }^{5}$

Place-based AR mobile gaming typically involves guiding or drawing players toward specific physical spaces using GPS locations on a digital map. The AR dimension involves orienting participants' attention to particular places or relevant features of the landscape and then augmenting their experience with semiotic resources, information, tasks, or prompts with the intention of creating an embodied and experiential in-the-world dynamic for participants (Holden \& Sykes, 2011; Thorne, 2013). As a technology-enabled approach, mobile AR activities would seem to

\footnotetext{
4 "MMOGs are immersive, graphically rich 3D environments in which many players from geographically distinct locations can navigate the game space and interact via digital characters known as avatars" (Rama et al., 2012, p. 213).

${ }^{5}$ Although not an AR environment per se, the European Digital Kitchen project described by Seedhouse et al. (2014) represents an experiential environment and is another example of a game-like environment and simulation.
} 
pedagogically support Wei's (2018) observation that "language learning is a process of embodied participation and resemiotization" (p. 17).

One of the first games to use AR technology for language teaching was Mentira (Holden \& Sykes, 2011), an AR place-based mobile game for Spanish created using an open source platform called ARIS (Augmented Reality for Interactive Storytelling; https://fielddaylab.org/ma $\mathrm{ke} / \mathrm{aris} /$ ). The game is set in a historically Spanish-speaking neighborhood in Albuquerque, New Mexico, where learners must solve a prohibition-era murder mystery. While playing the game, students complete a jigsaw-style activity in which each player receives different clues, requiring collaboration to complete the task (Holden \& Sykes, 2011). In another study, Perry (2015) described an AR game for French called Explorez, a quest-style game similar to Mentira. Perry pointed out that students made efforts to speak in French while playing the game and indicated that at times students' efforts to stay in the target language resulted in a "sociocultural learning effect" (p. 2313) in which a more advanced student helped supply the other student with the word or information they were searching for or helped correct the other student's language errors. In the context of academic language support, Liu and Tsai (2013) explored uses of an AR game for writing practice. Their findings indicate that learners utilized in-game vocabulary in their essays and improved their content knowledge of the topic of the game (description of a university campus).

In research on the place-based game used in this study (ChronoOps, described below), Thorne et al. (2015) investigated the interactional and linguistic practices used by groups of three participants to show how groups of ELL students sharing one smartphone orient to the device and the information it displays, develop practices for wayfinding, and use talk to bring shared attention to features of their physical surroundings. This research emphasized the importance of how the game moved the language experience out of the classroom and how the group dynamic around one device influenced students' interactional practices. In related research, Hellermann et al. (2017) described the complex interactions associated with the literacy event of reading aloud during mobile AR game play, illustrating that collaborative practices for playing the game that involved reading emerged and consolidated over the duration of the activity.

Two recent AR studies attended to socially and materially situated aspects of human action and communication. In a study of the placebased AR game Guardians of the Mo'o, Zheng et al. (2018) illustrated how "place evokes a learner's effort for making meaning and realizing values through embodied action, collaboration and coordination" ( $\mathrm{p}$. 55). Adopting an ecological perspective, Zheng et al. argued that "experiencing place is critical for learners to break away from institutional 
norms and previous thinking patterns in order to develop skilled linguistic action in actual events that lead to prospective actions" (p. 55). This is illustrated via wayfinding and resources learners use to do so, such as anchoring their next actions in what is physically present in their environment or asking a librarian for help. Thorne and Hellermann (2017) analyzed video data of AR game play and described how problems in understanding, as well as moving forward next actions, were often enmeshed with and supported by the physical environment. Their analysis demonstrated the relevance of embodied and distributed approaches to human activity, illustrating that participants utilize gaze, gesture, vocalizations and talk, pointing, and embodied deixis, in an orderly manner, to coordinate virtual-digital (iPhone) and sensory-visual information, to navigate to next locations, and to complete the oral narration tasks comprising the AR game.

As seen from the review above, previous studies on AR games largely focused on investigating the development of interactional competence (from either the sociocultural or the ecological perspective). To further expand the investigation of affordances of AR games for language learning, in this article we respond to Sert and Balaman's (2018) call to investigate form-focused negotiations of language. The next section explains how the LRE construct can be used to provide empirical evidence for whether and to what degree AR game players orient to language structures and produce meta-talk about their language use. Due to the history of LREs as a unit of analysis, we use a sociocultural approach that also draws inspiration from the ecological perspective and its emphasis on context, as outlined in van Lier (2004; see also Zheng et al., 2018).

\section{LREs as a Unit of Analysis}

LREs have been used as a unit of analysis in a variety of theoretical perspectives, but mainly the interaction approach and Vygotskian sociocultural theory. We focus on the latter theory. (For comparisons of use of LREs in the interaction approach and sociocultural theory, see Fernández Dobao, 2016; Sato \& Viveros, 2016.) In sociocultural theory, human development is viewed as a dynamic process involving engagement with historically formed cultural and linguistic practices, artifacts, milieus, and of course other people. Learning is understood as a mediated process "organized by cultural artifacts, activities and concepts" (Ratner, 2002, as cited in Lantolf, Thorne, \& Poehner, 2015, p. 207). Certain tasks and activity types, including games, can facilitate participants' involvement in the coconstruction of meaning, problem solving, and knowledge building through talk, all of which have been shown to create contexts for language development (Thorne, Black, \& Sykes, 2009). Such talk and interaction 
during tasks have been described as collaborative dialogue, or "dialogue in which speakers are engaged in problem solving and knowledge building. ... [D] uring collaborative dialogue, one or both speakers may refine their knowledge or come to a new or deeper understanding of a phenomenon" (Swain \& Watanabe, 2013, p. 1). Collaborative dialogue is a source of language development due to opportunities for the co-construction of meaning by interlocutors and the linguistic assistance they provide to each other (e.g., Brooks \& Swain, 2009; Swain \& Lapkin, 2002; Watanabe \& Swain, 2007, 2008; Zeng \& Takatsuka, 2009). Through collaborative dialogue, learners may collectively accomplish what they would not be capable of on their own. The key points during collaborative dialogue that have been theorized to be catalysts for learning have been operationalized as LREs: "any part of the dialogue where the students talk about the language they are producing, question their language use, or correct themselves or others" (Swain \& Lapkin, 1998, p. 326).

To illustrate how LREs can catalyze learning, Swain and Lapkin (1998) showed how a pair of students in a French immersion school completed a jigsaw task requiring them to collaboratively write a narrative. In 23 LREs from this pair of students, 21 resulted in the students coming to a correct solution. In a later study exploring French learners' use of LREs, Swain and Lapkin (2001) compared use of and types of LREs (lexis-based versus form-based) across two collaborative writing tasks. No significant differences in quantity of LREs between groups were found; however, the jigsaw, as a more open-ended task, was associated with a greater range of vocabulary use, whereas the dictogloss task stimulated greater accuracy with verbs, which were the linguistic focus of the class. Similar patterns were found in de la Colina and García Mayo (2007). These studies suggest that occurrence and types of LREs are affected by task design. In contrast, whereas Swain and Lapkin's studies were conducted in controlled classroom environments, Ryoo (2009) looked at students' LREs in a more relaxed conversational setting, analyzing the loosely structured interactions of an English conversation club. Ryoo first located LREs in the data, then searched for evidence of participants' target-like reuse of the items in later interactions. She argued that the learners' later independent and appropriate use of items recently emerging in LREs demonstrated that they were indeed learning by means of the LREs.

In addition to task type differences, seeing the process or quality of LREs is likewise important to understand how learning can occur via LREs. Storch (2008), Storch and Wigglesworth (2010), and García Mayo and Azkarai (2016) demonstrated that elaborate engagement, where participants "deliberated and discussed language items" (Storch, 2008 , p. 95) as opposed to provided immediate answers, was more facilitative of learning than limited engagement. The number of 
participants may also be influential. In a series of related studies, Fernández Dobao (2014a, 2014b) found that learners in groups of four were able to focus their attention on language more often than learner-learner dyads; groups were also more successful at solving language-related problems. Lasito and Storch (2013) obtained similar results. These findings suggest that there may be more opportunities for learning in small groups than in pairs.

Although there is an abundance of studies on learner-learner interaction, only two studies on collaborative dialogue, Fernández Dobao (2012) and Tocaimaza-Hatch (2016), examined learner-expert speaker interactions, both focusing on lexical LREs. Fernández Dobao observed that, overall, lexical LREs were more frequent and more likely to be resolved in expert-learner dyads; however, individual expert speakers differed on the kind of assistance they provided to learners. Like Watanabe and Swain (2007, 2008), Fernández Dobao found that

the participants' collaborative or non-collaborative orientation to the activity, shaped by their goals and level of involvement in the task, seems to have a stronger effect on the nature of the interaction and the opportunities this offers for LREs and learning than the overall proficiency of the dyad. (2012, p. 229)

Tocaimaza-Hatch similarly found that there was variation between dyads in terms of their level of engagement and the quantity and quality of lexical LREs, which impacted learning outcomes. These two studies suggest that even with the addition of expert speakers as interactants, group dynamics may be the primary factor in learning outcomes.

\section{Research Questions}

Although LREs have been the topic of investigation in much of the research on collaborative tasks, little is known about students' use of LREs during gaming, and in particular about collaborative dialogue during mobile game play in learner-expert speaker groups. To better understand the affordances for learning, this study investigated students' use of LREs while playing ChronoOps, an AR place-based mobile game. Given prior research on the potential benefit of working in groups (Lasito \& Storch, 2013), the ecological validity of completing language learning tasks in groups in non-instructional spaces (Zheng et al., 2018), and the paucity of research on collaborative dialogue between learners and expert speakers, we examined LREs in mixed groups of three participants: two learners and one expert speaker. The study addressed the following research questions: 
1. Do LREs occur in AR game play? If so, what patterns are visible with regard to their structural properties (lexis versus form)?

2. What discursive trajectory do LREs take in expert speaker-learner interaction?

3. Is there evidence of subsequent use of LRE-implicated forms later in game play?

The research questions were designed to elucidate affordances of AR games played in expert speaker-language learner groups from the perspective of sociocultural theory, and in particular in light of such concepts as self- and other-regulation, assistance, mediation via cultural artifacts, and co-construction of meaning. Inspired by the ecological perspective, we also highlight LREs that illustrated participants' orientation to the relevance of place.

\section{METHOD}

This is a descriptive study exploring meta-awareness and explicit attention to language form, function, or meaning in the context of AR games. For the purposes of broad description, we first divided LREs into categories commonly used in LRE-related studies, such as focus on lexis or grammar, resolved or not, and so on. In the second part of our analysis, we used conversation analysis (CA) methodology to illustrate the microgenesis of learning through interaction.

\section{Participants}

Four groups of three students (two ELLs and one ESE in each group) participated in this study. ELLs, ranging in proficiency from intermediate to advanced, were enrolled in an intensive English language program in the United States. ESEs were students in a mixed upper division undergraduate/graduate second language acquisition course, a course required for preservice ESL teachers.

\section{Materials}

ChronoOps constituted the pedagogical intervention investigated in this study. ChronoOps ${ }^{6}$ is a quest-type mobile AR game that is

\footnotetext{
${ }^{6}$ ChronoOps was developed at Portland State University by the 503 Design Collective (https://www.pdx.edu/linguistics/503-design-collective), a group of faculty and students focusing on technology-oriented research and the design and development of pedagogical interventions.
} 
currently available in seven languages, including English. The game scenario emphasizes green technology and environmental sustainability projects as its core focus. The participants play the role of an agent from the future, and the game begins by describing that in the year 2070 the planet has suffered massive environmental degradation and they (the player-agents) have been sent back in time to the present year in order to learn from the green technology projects that are in evidence on and around the university campus. The game is played by accessing instructions on a mobile phone, one per group of three players, which instructs players to find five designated green technology sites on the campus. Once found, students file video reports that describe the advantages and disadvantages of the green technologies they encountered in the hopes that this information can be used to help reverse the environmental catastrophe that is this planet's future. In this sense, ChronoOps falls within the narrative genre of digital games due to the emplacement of the AR game mechanics (i.e., route finding between green technology locations with the goal of submitting video reports to an artificial intelligence from the future in order to save the planet) within a postapocalyptic story line. ChronoOps was intentionally designed as a series of open-ended, underspecified tasks. The pedagogical motivation was to have players agentively construct their actions in interaction with the game goals and content. (For more details on ChronoOps, see Thorne, 2013; Thorne et al., 2015.)

\section{Procedures}

ELLs and ESEs met in the ELLs' classroom, were put into groups by their instructors, ${ }^{7}$ and two volunteers from each group were then equipped with head-mounted video cameras and microphones. Researchers then began recording their assigned group of students using a third handheld camera. The groups were provided with a handout explaining how to play the game and were oriented to the activity in the classroom before starting to play (see the online Supporting Information for full details of the intervention procedures).

\section{Analysis}

First, video recordings of each group's interaction were transcribed using CA conventions (Jefferson, 2004). Next, LREs were identified within each group following Swain and Lapkin's (1998) definition

\footnotetext{
${ }^{7}$ The participants were divided in a way that no participants shared the same L1 in each group.
} 
cited earlier. Finally, after preliminary analysis, the LREs were categorized and coded to understand who initiated LREs, which discourse moves were used to initiate them (Zeng \& Takatsuka, 2009), and what language structures were the targets: lexis (word meaning or pronunciation, as in McDonough \& Sunitham, 2009) or form (morphology or syntax, as in Storch, 2008). When coding discourse moves for LRE initiation, we applied Williams's (1999) categorization of learner-initiated LREs: learner-initiated requests for assistance, negotiation over a language item, metatalk, and other correction. We applied these to both learner-initiated and expert speaker-initiated LREs.

For coding the resolution of LREs, we followed the frequently used system of correctly resolved, incorrectly resolved, and unresolved LREs (e.g., McDonough \& Sunitham, 2009; Storch, 2008). As a measure of learning, following Ryoo (2009) and Swain and Lapkin (1998), we adopted a microgenetic approach to track qualitative changes in cognition and performance over a short period of time. Using this approach, we investigated subsequent use of the negotiated co-constructed language from the LREs and coded those examples as targetlike or not target-like. Additionally, opportunities for LREs during the groups' interactions that were not taken up were categorized as let-itpass moments (Firth, 1996). Examples of the coding categories (LRE types and resolution) and an example of a let-it-pass moment also can be found in online Supporting Information.

\section{RESULTS}

\section{Research Question 1}

Table 1 shows the occurrences of LREs for each group and what they focused on (lexis or form). LREs occurred in all four groups. During approximately the same amount of time playing the game, two of the groups (1 and 4) produced 11 LREs and the other two (2 and 3) produced five LREs each.

Table 1 also shows that the focus of LREs was on lexis, which suggests that participants viewed the task as meaning oriented. None of

\footnotetext{
${ }^{8}$ For the purposes of description, we adopted some coding categories from the interactionist tradition (e.g., Williams, 1999). However, these have also been widely used in research on LREs from the sociocultural perspective. Additionally, CA researchers Sert and Balaman (2018) concluded that negotiation of meaning "as an essential constituent of cognitivist/interactionist SLA ... is indeed a catalyst for learning as revealed by the participants' developed interactional competencies in this L2 context" (p. 15). That is, although we primarily adopt the sociocultural approach in our analysis, we also align with Sert and Balaman in that we do not shy away from making connections to other approaches and methodologies where they are warranted.
} 
TABLE 1

Language-Related Episode (LRE) Occurrence and Structural Properties per Group

\begin{tabular}{lcl}
\hline \hline & Total LREs & Structural property \\
\hline Group 1 & 11 & 11 lexis \\
\hline Group 2 & 5 & 4 lexis \\
& & 1 target unclear \\
\hline Group 3 & 5 & 5 lexis \\
\hline Group 4 & 11 & 9 lexis \\
& & 2 target unclear \\
\hline
\end{tabular}

the 32 LREs addressed form. Three LREs were unclear with regard to the particular difficulty that arose; in some of these unclear LREs, participants questioned in-game instructions but did not single out a specific lexical or grammatical form.

In terms of specific lexical targets that LREs addressed, we observed an element of unpredictability. Some lexical items pertained to green technology (as indicated by in-game instructions), such as rainwater, bike racks, solar panels, and turbines, or difficulties with in-game prompts, such as beginning of the end. However, other lexical targets indicate that the place-based nature of the AR activity can provide opportunities for exploration of language. In Excerpt 1, the group is walking to destination 2, where they will report on solar energy located on the roof of a prominent campus building named Lincoln Hall. As they walk, ELL1 asks about the war that Lincoln was involved in (line 1). ESE gives the word (civil) in line 4 that ELL1 repeats in line 5.

\section{Excerpt 1}

01 ELL1: how to say the wa: :r that Lincoln (did).

02 ESE: Lincoln president?

03 ELL1: yeah the war he did, he did.

04 ESE: aoh the civil war.

05 ELL1: civil war.=

06 ESE: =yeah the American civil war.

Just prior to this example, when the task prompt text in the game indicated Lincoln Hall as the location for the next report, ESE asked if the other two participants knew who Lincoln was, which made ELL1's question in line $1 \mathrm{a}$ relevant one to ask at that time. 


\section{Research Question 2}

First, we examined who initiated the LREs and how. Out of 32 LREs in the four groups, almost a third (10) were initiated by ESEs (see Table 2). How LREs were initiated and by whom sheds more light on this finding: Only ELLs used requests for assistance, and only ESEs used recasts, corrections, and comprehension checks. Both ELLs and ESEs used clarification requests. Notably, the participant initiating the LRE varied greatly across groups. In group 1, for example, the ESE did not initiate any LREs, whereas in group 4 the ESE initiated three quarters of them.

Next, we examined the resolution of LREs. Following previous research on learner-expert speaker interactions (Fernández Dobao, 2012; Tocaimaza-Hatch, 2016), we expected that most LREs would be

TABLE 2

Initiation of, Resolution of, Subsequent Use of, and Potential for Language-Related Episodes (LREs)

\begin{tabular}{|c|c|c|c|c|}
\hline & $\begin{array}{c}\text { Initiator and } \\
\text { discourse move }\end{array}$ & Resolution & Subsequent use & $\begin{array}{l}\text { Potential } \\
\text { for LREs }\end{array}$ \\
\hline Group 1 & $\begin{array}{l}\text { ELL 01: } \\
8 \text { assistance requests } \\
3 \text { clarification requests }\end{array}$ & $\begin{array}{l}82 \%(9 / 11) \\
\text { correct } \\
18 \%(2 / 11) \\
\text { unresolved }\end{array}$ & $\begin{array}{l}4 \text { correct } \\
\text { (by initiator) }\end{array}$ & 3 let-it-pass \\
\hline Group 2 & $\begin{array}{l}\text { ELL } 01: \\
2 \text { assistance requests } \\
\text { ELL 02: } \\
1 \text { assistance request } \\
1 \text { clarification request } \\
\text { ESE: } \\
1 \text { recast }\end{array}$ & $\begin{array}{l}100 \%(5 / 5) \\
\text { correct }\end{array}$ & $\begin{array}{l}3 \text { correct } \\
\text { (by initiator) }\end{array}$ & 2 let-it-pass \\
\hline Group 3 & $\begin{array}{l}\text { ELL } 01: \\
2 \text { assistance requests } \\
\text { ELL } 02: \\
2 \text { assistance requests } \\
\text { ESE: } \\
1 \text { correction }\end{array}$ & $\begin{array}{l}60 \%(3 / 5) \\
\text { correct } \\
20 \%(1 / 5) \\
\text { incorrect } \\
20 \%(1 / 5) \\
\text { unresolved }\end{array}$ & $\begin{array}{l}3 \text { correct } \\
\text { ( } 2 \text { by initiator, } \\
1 \text { by another ELL) } \\
1 \text { incorrect } \\
\text { (by another ELL) }\end{array}$ & 2 let-it-pass \\
\hline Group 4 & $\begin{array}{l}\text { ELL } 01 \text { : } \\
3 \text { assistance requests } \\
\text { ESE: } \\
1 \text { recast } \\
4 \text { comprehension checks } \\
1 \text { clarification request } \\
\text { ESE and ELL } 01: \\
2 \text { clarification requests }\end{array}$ & $\begin{array}{l}73 \%(8 / 11) \\
\text { correct } \\
27 \%(3 / 11) \\
\text { unresolved }\end{array}$ & & \\
\hline
\end{tabular}


resolved. However, $22 \%$ of the LREs remained unresolved or incorrectly resolved ( 7 of 32 for all groups combined). Therefore, we conducted further analysis to understand possible reasons for the lack of resolution. We found that the resolution depends on the kind of lexical item and how well it could be explained given the local context. For example, when learners pointed to bicycle racks and asked what they are called, expert speakers were able to provide target-like answers. However, when a learner, whose code name for the purposes of the game was Fern, questioned the meaning of the word fern, an expert speaker described it as a "bushy plant," "some of them are big, some are small." Without a visual of a fern, this was likely not a clear explanation. Although players frequently used the place-based nature of the game to their advantage (pointing to bike racks or talking about the civil war as invoked by the Lincoln Hall landmark), they did not do so in the fern example although ferns were abundant in their immediate environment. (The fern example took place at the very beginning of game play, so it is possible that the players had not yet become fully aware of the affordances of the place-based nature of the activity).

Another factor that may contribute to the resolution of LREs is participants' orientation to the task as it is embedded in the larger game activity. Some interlocutors appeared to be more interested in progressing within the game as long as there were no disruptive misunderstandings in meaning. For example, as indicated in Excerpt 2, ELL1's question of whether solar screen is the right term is affirmed by the ESE although solar panel would be a more typical expression in American English. However, other participants were, at least at times, focused on target-like forms. This is illustrated in Excerpt 3, where the recast fuel by the ESE occurs in line 4 .

\section{Excerpt 2}

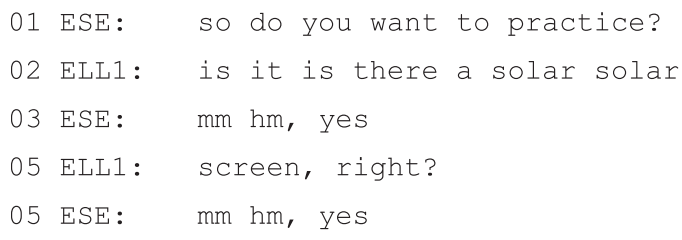




\section{Research Question 3}

Using microgenetic analysis, we searched to see if LRE-implicated forms were used subsequently in game play. Thirty-four percent of the LREs were used later (10 were target-like and one was not target-like). Although subsequent use appears rather low, the changing participant framework can account for that. In some instances an ELL initiated an LRE during the planning of an upcoming report for a given location (e.g., seeking confirmation that solar panels is the right term); however, in the report that followed the planning it was an ESE's turn to speak during the report that included the target solar panels and thus there was no opportunity for an initiator to subsequently use the LRE-implicated form. ${ }^{9}$

Although the subsequent use of target-like structures did not constitute a high proportion of LREs in the quantitative analysis, examining particular interactions can provide evidence for the unfolding microgenetic processes of learning. Using CA, in Excerpts $4 a-4 d$ we present excerpts from one extended LRE of about eight minutes that included several embedded LREs. The overarching LRE involved group members discussing the meaning of the phrase the beginning of the end that appeared in the game instructions for location 3. Because the group needed to provide a videorecorded report as their response to the prompt, and because it seemed that the expert speaker was not going to do that report (she had just recorded the report at location 2), ELL2, being a potential reporter for this location, made significant efforts to understand what the phrase meant. The excerpts illustrate the way mediated interaction can lead a novice from other-regulation (help required from another person to complete a task or action) to self-regulation (autonomous ability to carry out a task or action).

In location 3 of the task, players found themselves at a site formerly called Electric Avenue, a street on which electric cars used to be able to park with free access to charging stations. When the electric car charging site was displaced to construct a new building in its place, the game continued to display the photo of the now missing electric car charging stations. The game narrative described what used to be at the site and asked players to speculate on whether they thought this new construction was an example of "the beginning of the end of green technology." At the start of the excerpt, after ESE reads the instructions from the game (lines 4-6), ELL2 displays her need for assistance by reading part of what ESE

\footnotetext{
${ }^{9}$ There was only one incorrectly resolved LRE, and it was also incorrect in subsequent use (see Table 2). Since ELLs were the only ones making requests for assistance, it appears that they viewed expert speakers as more knowledgeable and thus incorporated the LRE incorrectly resolved by the expert speaker.
} 
had just read and then explicitly indicates a lack of understanding (lines 10-11). ESE begins her explanation in lines 12-21, at which point she checks on ELLs' understanding. (Bold text in the transcript indicates text that is read aloud.)

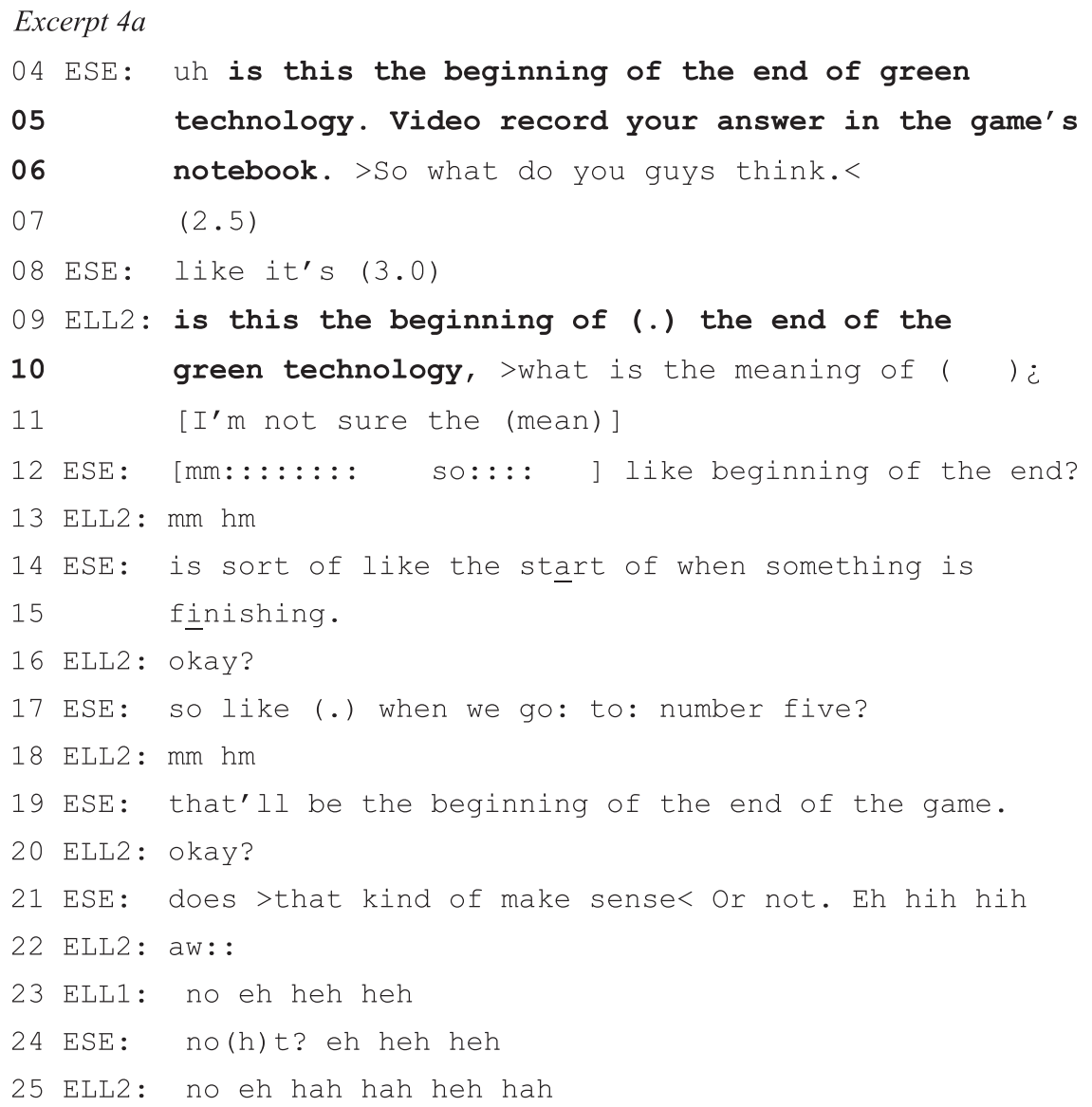

When the learners indicate they are still not understanding (lines 23 and 25), ESE continues (Excerpt 4b) with the explanation, this time incorporating a closure gesture (palms down, parallel to ground, moving away from one another) to give an embodied clue to the meaning (line 31, Figures 1 and 2). After some talk about the new building's construction site across the street, ELL2 gives her understanding of what ESE had explained using a cutting kind of gesture, right hand perpendicular to the ground, coming down on the left hand, which is parallel to the ground (line 80, Figures 3 and 4), which ESE confirms in line 83 repeating the same cutting gesture (Figure 5). 
It appears that the embodied discussion mediates ELL2's understanding of the phrase as she produces her understanding (lines 80 and 82 ) with the gesture and vocalization of two synonyms ("stopping or finishing").

Excerpt $4 b$

28 ESE: it's saying like (.) will this be finishing

29 ELL2: $\mathrm{mm} \mathrm{hmi}$

30 ESE: like, is green technology now: (.) stopping.

31 ^like

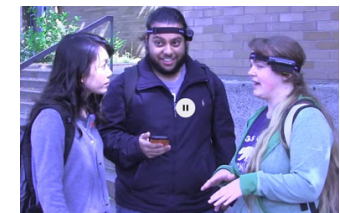

$\wedge$ Figure 1.Start of ESE's closing gesture.

[Colour figure can be viewed at wileyonlinelibrary.com]

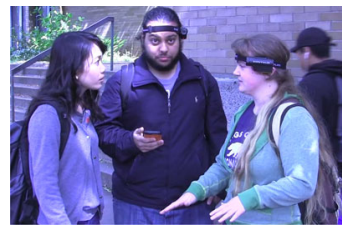

Figure 2. End of ESE's

[Colour figure can be viewed at wileyonlinelibrary.com]

32 ELL2: oh [:: :

33 ESE: [is it starting to decline and go [down and not be

34 ELL2:

[ok ok

35 ESE: used as mu[ch because no longer are: : there electric

36 ELL2: [uh huh

37 ESE: cars being charged here instead they're [having a

38 ELL2:

$[\uparrow h m$

39 ESE: construction zone.

40 ELL2: ok

((lines not included - speculation about the construction site))

80 ELL2: so end is *like

*stopping

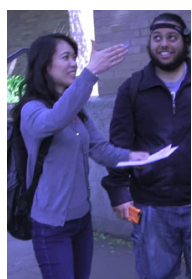

${ }^{*}$ Figure 3.

Start of ELL2's cutting gesture.

[Colour figure can be viewed at wileyonlinelibrary.com]

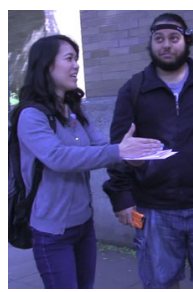

${ }^{*}$ Figure 4.

End of ELL2's cutting gesture.

[Colour figure can be viewed at wileyonlinelibrary.com] 

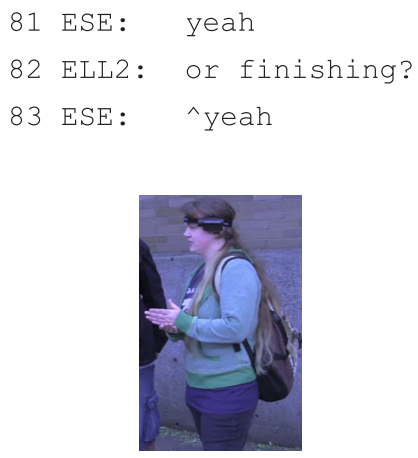

^Figure 5.

ESE's repetition of cutting gesture.

[Colour figure can be viewed at wileyonlinelibrary.com]

During the group's discussion about making their report (Excerpt 4c), ESE refers again to the phrase in the task prompt ("beginning of the end") and then indicates (lines 95-96) that a "simple" version of beginning of the end would be the word "cease." ELL2 makes a clarification request (line 97) and ESE gives a synonym ("end") using the same cutting gesture (line 100, Figure 6) that ELL2 used first in Excerpt 4b. ELL2 indicates a change of state (line 102) and then repeats the cutting gesture with the hands reversed (lower hand vertical moving up to meet the horizontal hand, Figures 7 and 8). ESE displays her expert status by offering the spelling of the word (line 106) and the group then spends another couple of minutes determining who will make the report.

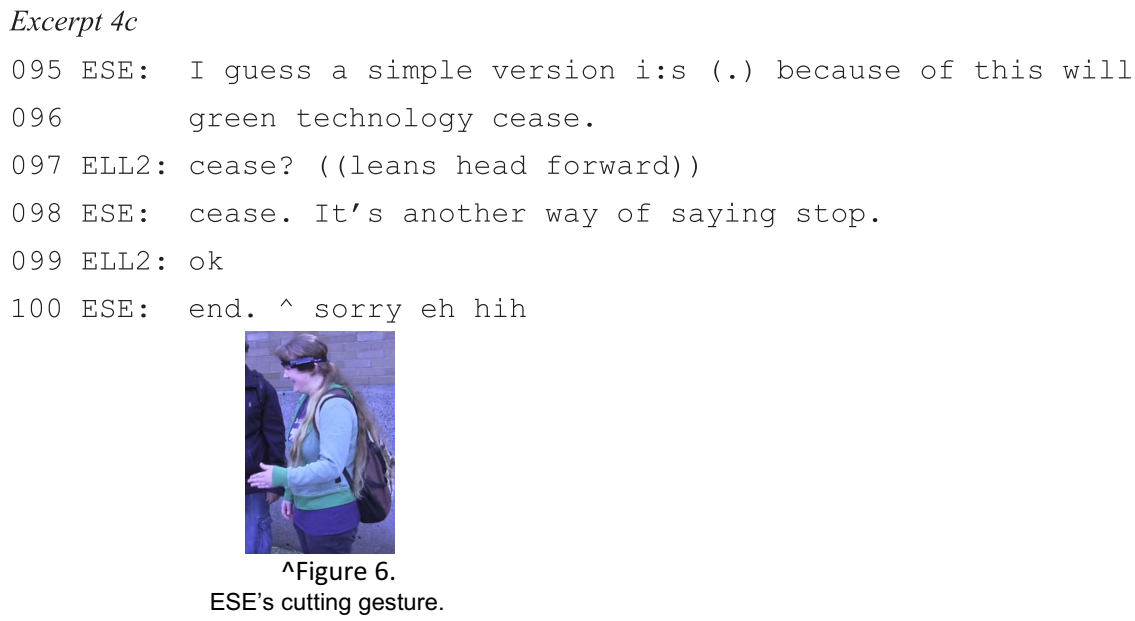

$\wedge$ Figure 6

ESE's cutting gesture.

[Colour figure can be viewed at wileyonlinelibrary.com] 


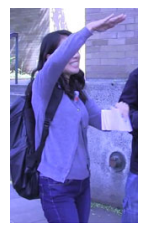

*Figure 7.

Start of ELL2's cutting gesture.

[Colour figure can be viewed at wileyonlinelibrary.com]

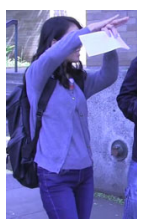

Figure 8. End of ELL2's cutting gesture.

[Colour figure can be viewed at wileyonlinelibrary.com]

103 right?

104 ESE: cease.

105 ELL2: cease. 'okํำ

106 ESE: c-e-a-s-e ((spelling))

107 ELL2: c-e-a:-s-e cease

((group discusses who will make the report))

In that discussion, it is determined that ELL2 - the student who had initiated the LRE in Excerpt 4a, line 9-will make the report, which begins in Excerpt $4 d$, line 200. In the report, she references the construction going on just behind her (line 200) showing the influence of the environment on language for interaction in a place-based activity (Hellermann, Thorne, \& Haley, in press). She also attempts to use the new word in her report (line 204) and produces an approximation with rising intonation that is heard by ESE as a trouble source. ESE corrects the pronunciation (line 205) and ELL2 repeats that pronunciation (line 206), which ends the report.

\section{Excerpt $4 d$}

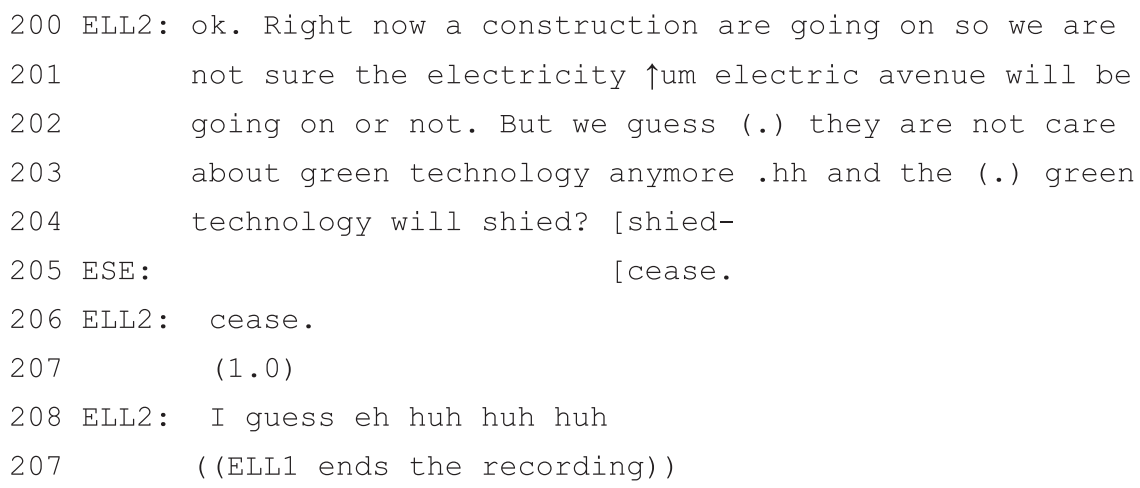


As Excerpts 4a-4d illustrate, both ELLs had difficulty understanding (lines 23 and 25) what the expression the beginning of the end meant in the context of the game and standing in front of a construction site. This excerpt series illustrates how ESE then provided involved explanations using gestures and verbal examples to help the ELLs understand the phrase. We see evidence of learning in that ELL2, albeit after 8 minutes, was able to produce a relatively clear report that indicated the understanding of the concept beginning of the end. Additionally, there is evidence of learning the word cease in that during the report, ELL2 independently attempted to produce it in a correct context and then reproduced the standard pronunciation after being corrected by ESE. The length of the LRE and the embodied negotiation of meaning involved are important illustrations of the co-constructed deep processing that accompany many LREs and are useful measures of learning. We return to this point in the discussion.

Although not one of the research questions for this article, our observation of the recurrent influence of the surrounding environment on game players and their interactions (as noted in Excerpts 1 and $4 \mathrm{~d}$ ) is central to the place-based aspect of AR activities. Groups noticed and made relevant to their actions a number of environmental features, such as a solar-powered trash can, a streetcar, and a fountain. None of these artifacts were written into the game, but each became relevant for interaction because of their perceptual salience and the sense made out of them (in relation to the game) by the players. For example, when passing the trash can and the streetcar, players discussed those items as possible examples of green technology. When players were asked to discuss ways that rainwater could be collected and used, they were positioned near a fountain with a waterfall and they subsequently looked at the waterfall and extemporaneously discussed the use of turbines to create hydroelectric power.

\section{DISCUSSION}

As evidenced by the occurrence of LREs in the context of an AR place-based mobile game, participants attended to language as part of the accomplishment of tasks embedded in the postapocalyptic green technology themed game narrative. However, unlike more frequently studied structured task interactions (jigsaw [Swain \& Lapkin, 2001], dictogloss [García Mayo \& Azkarai, 2016], or collaborative writing [Swain \& Lapkin, 1998]), where learners focus on both lexis and form, in our open-ended AR game activity we observed only focus on lexis. Although learners more typically focus on meaning over formal 
accuracy unless their attention is explicitly brought to form (e.g., Tarone, 2009; Williams, 1999), especially in spoken tasks (see García Mayo \& Azkarai, 2016, for a review), absolute absence of form-focused LREs in our data is notable. This was surprising given that in previous research on LREs in loosely structured interactions (Ryoo, 2009), learners focused both on lexis and form. One explanation could be the nature of the context for the interaction where one of our participants' goals involved finishing the game in a timely manner. Therefore, it is plausible that players used a let-it-pass strategy and initiated LREs (e.g., beginning of the end, solar panels, bike racks) only when meaning was necessary for making their recorded report, a practice that mirrors everyday communicative interaction.

The LREs were also influenced by the place-based nature of the game. For example, when one group approached a building named in the game (Lincoln Hall), an ELL asked a question about civil war due to the indirect connection of the name of the building with the name of the president (Lincoln) and the war associated with him. An important finding is that in such open-ended AR tasks, there is room for participants' creativity in terms of how they approach and carry out tasks and assemble a diversity of perceptually available affordances. The occurrence of LREs focused on lexical items invoked by the physical place additionally follows the TBLT principle of using language in authentic and real tasks. Although talk about the civil war was not related to green technology (the topic of the game), it was authentic and prompted by contextual relevance (in this case, historical nomenclature). Additionally, the abundance of LREs on lexical items concerning the game theme (green technology) is in accordance with the TBLT principle that tasks benefit from embedding within salient topical and physical context (see González-Lloret, 2015). That is, the focus on topical lexical items necessitated by the game synergistically combined with physical and semiotic contexts of relevance together created conditions for sense-saturated and hypercontextualized talk-ininteraction (Thorne \& Hellermann, 2017).

With regard to ESE/ELL patterns of interaction, we found differences between groups on LRE initiation, which is in line with prior findings that pair and group dynamics inevitably vary (Fernández Dobao, 2016; Watanabe \& Swain, 2007). On the other hand, a consistent pattern was that ELLs initiated LREs via requests for assistance, whreas ESEs provided corrections and confirmations. Thus, it appears that ELLs positioned themselves as less knowledgeable in English, and ESEs positioned themselves as more knowledgeable (a similar distribution of checks [e.g., for information, comprehension] and requests [e.g., for information, clarification] between knowing and unknowing participants was obtained in Balaman \& Sert, 2017). We suspect that 
ESEs' orientation to the task was more in the role of teachers than collaborative group members (examined further in a paper under review) and that ESEs may have been seeing themselves as facilitators of the task rather than fellow game players, or teachers as providers of targetlike English. Although ESEs' roles were not explicitly stated before the commencement of the activity, given that all ESEs were in a teachertraining program taking on a teacher identity is a reasonable expectation. As facilitators rather than explicit teachers, ESEs did not always provide target-like resolutions of LREs and may have leaned toward a let-it-pass strategy to maintain progressivity so that tasks moved forward. However, expert speakers of a language do not always take on an expert role, and expert/novice roles (or more vs. less knowledgeable) can dynamically shift during an interaction (e.g., Thorne \& Hellermann, 2015; Zuengler \& Bent, 1991). Had some players had more experience with the particular game or more prior knowledge of green technology than others, shifting patterns of expert-novice interactions may have been visible. ${ }^{10}$

Regarding the third research question, the examination of subsequent use indicated that learning of LRE-implicated forms did occur in the case of lexis. We also demonstrated, in an analysis of an 8-minute example of an LRE (Excerpts $4 \mathrm{a}-4 \mathrm{~d}$ ), the learning process and collaborative co-construction of meaning that can occur as part of participation in place-based AR game play. This co-construction of knowledge helped at least one ELL understand the meaning of the phrase beginning of the end. Because depth of processing (Leow \& Mercer, 2015) and elaborate engagement (García Mayo \& Azkarai, 2016; Storch, 2008; Storch \& Wigglesworth, 2010) positively affect L2 learning, further investigation of such elaborated LREs is warranted.

\section{CONCLUSION}

In this article, we examined how LREs provided opportunities for language learning as they emerged during interaction in the context of a mobile place-based AR game. Along with the findings we presented are implications for future research and pedagogical interventions. Given that all LREs in our data were related to lexis, AR games can be considered a meaning-oriented language learning task (Ellis, 2003) unless focus on grammar is explicitly woven into the task via instructions or participants' individual goals. Furthermore, because

\footnotetext{
${ }^{10}$ In fact, in a paper under review, we observed that although ESEs primarily took on expert roles, some of them displayed their unknowing status with regard to maps and wayfinding.
} 
LRE targets were determined by the participants rather than preplanned by instructors or game designers, AR tasks as represented in our data appear to create opportunities for just-in-time and situationally driven vocabulary learning. Moreover, because most LREs focused on lexis relevant to the particular topic of green technology (e.g., bike racks, solar panels, fuel, water recycling), game design can be strategically organized by instructors to emphasize and make relevant vocabulary items that they want their learners to focus on. Prior research (Kim, 2008) indicates that incidental vocabulary learning can be effective in pairs in classroom contexts. Our study provides evidence that AR game play with groups containing both expert speakers and learners also presents facilitative contexts for such learning and is particularly helpful for collaborative deconstruction of the meaning of abstract concepts, such as the beginning of the end, especially when such concepts are supported via aspects of place and as consonant with, and informed by, the game narrative. Our ongoing research is examining whether (and to what degree) incidental vocabulary learning occurs when AR games are played in groups of language learners.

We have only begun to explore the learning affordances of intentionally open-ended and contextually designed AR activities in which participants have relative freedom to construct the task and develop their own goals. Future studies could explore how more specific instructions (e.g., "learn as many new words about green technology as you can," "focus on the accuracy of your video report") might change the nature of game play and learning outcomes. Additionally, although there have been some investigations of experiential learning (Hellermann et al., 2017; Riley \& Douglas, 2016), our knowledge regarding how learning "in the wild," that is, situated in open social spaces outside of conventionally structured classrooms (Hellermann et al., forthcoming; Thorne, 2010), may differ from classroom-based learning is limited. For example, might learners have richer and more elaborated topical discussions in contexts of high relevance (e.g., discussing bicycle commuting while standing in front of campus bicycle racks) than when similar prompts for discussion are given inside the classroom? In a similar vein, is introduced or new vocabulary better retained when learned under condition of intense contextual relevance? Finally, to delimit the scope of analysis for this article, we focused only on processes of language learning as operationalized by LREs. However, games can contribute to learning in a number of other ways, including increasing engagement (e.g., Thorne, 2012a) and enabling opportunities to collaboratively generate and utilize elements of language to accomplish the superordinate goal of completing tasks related to the game (Sykes, Reinhardt, \& Thorne, 2010; Thorne, 2008). We are interested in continuing to explore the degree to which 
participants enact roles suggested by a game's story structure or narrative arc (in our case, agents from the future tasked with learning about green technology and environmental stewardship to help their future planet survive) and to investigate if and/or how role commitment aligns with the concept of willingness to communicate (e.g., MacIntyre, Dörnyei, Clément, \& Noels, 1998). The research presented above can also be used as a starting point for further investigating learners' contingent sense of self-efficacy in interacting with expert speakers.

In the arena of locative media using mobile place-based AR approaches, there is much left to investigate in terms of group composition, the effects of narrow and open task design, (intentionally) underspecified or highly specified formulation of instructions, and the relationship of language use to language learning in the structured unpredictability that governs guided movement through open social spaces. Because this study examined in detail only one mobile placebased game-informed intervention, we encourage and invite researchers and educators to explore the rapidly expanding collection of available locative media and the space- and place-based pedagogies they make possible.

\section{THE AUTHORS}

Tetyana Sydorenko is an assistant professor of applied linguistics at Portland State University. Her research interests include L2 pragmatics, computer-assisted language learning, learning in interaction, psycholinguistic processes in second language acquisition, and assessment. She is currently investigating the use of adaptive computer-simulated conversations in the teaching of L2 pragmatics.

John Hellermann teaches and does research in the areas of language use, linguistic theory, discourse analysis, and learning. He has used conversation analysis to investigate the role of co-constructed language for language socialization and learning in high schools and community colleges.

Steven L. Thorne is a professor of second language acquisition in the Department of World Languages and Literatures at Portland State University, with a secondary appointment in the Department of Applied Linguistics at the University of Groningen.

Vanessa Howe is an English language instructor in the English Preparatory Program at Bilkent University, in Ankara, Turkey.

\section{REFERENCES}

Balaman, U., \& Sert, O. (2017). Development of L2 interactional resources for online collaborative task accomplishment. Computer Assisted Language Learning, 30, 601-630. https://doi.org/10.1080/09588221.2017.1334667 
Berns, A., Gonzalez-Pardo, A., \& Camacho, D. (2013). Game-like language learning in 3-D virtual environments. Computers and Education, 60(1), 210-220. https://

Brooks, L., \& Swain, M. (2009). Languaging in collaborative writing: Creation of and response to expertise. In A. Mackey \& C. Polio (Eds.), Multiple perspectives on interaction: Second language research in honor of Susan M. Gass (pp. 58-89). New York, NY: Routledge. https://doi.org/10.4324/9780203880852

Dahlstrom, E., Brooks, D. C., Grajek, S., \& Reeves, J. (2015). ECAR study of students and information technology, 2015. Retrieved from http://net.educause.edu/ir/lib rary/pdf/ss15/ers1510ss.pdf

de la Colina, A. A., \& García Mayo, M. (2007). Attention to form across collaborative tasks by low-proficiency learners in an EFL setting. In M. P. García Mayo (Ed.), Investigating tasks in formal language learning (pp. 91-116). Clevedon, England: Multilingual Matters.

Ellis, R. (2003). Task-based language learning and teaching. Oxford, England: Oxford University Press.

Fernández Dobao, A. (2012). Collaborative dialogue in learner-learner and learner-native speaker interaction. Applied Linguistics, 33, 229-256. https://doi. org/10.1093/applin/ams002

Fernández Dobao, A. (2014a). Attention to form in collaborative writing tasks: Comparing pair and small group interaction. Canadian Modern Language Review, 14, 158-187. https://doi.org/10.3138/cmlr.1768

Fernández Dobao, A. (2014b). Vocabulary learning in collaborative tasks: A comparison of pair and small group work. Language Teaching Research, 18, 423-424. https://

Fernández Dobao, A. (2016). Peer interaction and learning: A focus on the silent learner. In M. Sato \& S. Ballinger (Eds.), Peer interaction and second language learning: Pedagogical potential and research agenda (pp. 33-61). Amsterdam, Netherlands: John Benjamins. https://

Firth, A. (1996). The discursive accomplishment of normality: On "lingua franca" English and conversation analysis. Journal of Pragmatics, 26, 237-259. https:// doi.org/10.1016/0378-2166(96)00014-8

Frith, J. (2015). Smartphones as locative media. Cambridge, England: Polity Press.

García Mayo, M., \& Azkarai, A. (2016). EFL task-based interaction: Does task modality impact on language-related episodes? In M. Sato \& S. Ballinger (Eds.), Peer interaction and second language learning: Research agenda and pedagogical implications (pp. 241-264). Amsterdam, Netherlands: John Benjamins. https://

Global Games Market. (2016). Retrieved from https://newzoo.com/insights/artic les/global-games-market-reaches-99-6-billion-2016-mobile-generating-37/

Godwin-Jones, R. (2016). Augmented reality and language learning: From annotated vocabulary to place-based mobile games. Language Learning and Technology, 20(3), 9-19.

González-Lloret, M. (2015). A practical guide to integrating technology into task-based language teaching. Washington, DC: Georgetown University Press.

González-Lloret, M., \& Ortega, L. (2014). Towards technology-mediated TBLT: An introduction. In M. González-Lloret \& L. Ortega (Eds.), Technology-mediated TBLT: Researching technology and tasks (pp. 1-21). Amsterdam, Netherlands: John Benjamins. https://doi.org/10.1075/tblt.6.01gon

Hellermann, J., Thorne, S. L., \& Fodor, P. (2017). Mobile reading as social and embodied practice. Classroom Discourse, 8(2), 99-121. https://doi.org/10.1080/ 19463014.2017.1328703

Hellermann, J., Thorne, S. L., \& Haley, J. (in press). Building socio-environmental infrastructures for learning in the wild. In J. Hellermann, S. Eskildsen, S. 
Pekarek Doehler, \& A. Piirainen-Marsh (Eds.), Language in action: CA studies of learning in the wild. Cham, Switzerland: Springer.

Holden, C., Dikkers, S., Martin, J., \& Litts, B. (2015). Mobile media learning: Innovation and inspiration. Pittsburgh, PA: ETC Press. Retrieved from http://reposi tory.cmu.edu/cgi/viewcontent.cgi?article $=1033 \&$ context $=$ etcpress

Holden, C. L., \& Sykes, J. M. (2011). Leveraging mobile games for place-based language learning. International Journal of Game-Based Learning, 1(2), 1-18. https://

Jefferson, G. (2004). Glossary of transcript symbols with an introduction. In G. H. Lerner (Ed.), Conversation analysis: Studies from the first generation (pp. 13-31). Amsterdam, Netherlands: John Benjamins. https://

Johnson, L., Adams Becker, S., Cummins, M., Estrada, V., Freeman, A., \& Hall, C. (2016). NMC Horizon Report: 2016 Higher Education Edition. Austin, TX: New Media Consortium.

Kim, Y. (2008). The contribution of collaborative and individual tasks to the acquisition of L2 vocabulary. Modern Language Journal, 92, 114-130. https:/ /

Lantolf, J., Thorne, S. L., \& Poehner, M. (2015). Sociocultural theory and second language development. In B. van Patten \& J. Williams (Eds.), Theories in Second Language Acquisition (pp. 207-226). New York: Routledge.

Lasito , \& Storch, N. (2013). Comparing pair and small group interactions on oral tasks. RELC Journal, 44, 361-375. https://

Leow, R. P., \& Mercer, J. D. (2015). Depth of processing in L2 learning: Theory, research, and pedagogy. Journal of Spanish Language Teaching, 2(1), 69-82. https://doi.org/10.1080/23247797.2015.1026644

Liu, P. E., \& Tsai, M. (2013). Using augmented-reality-based mobile learning material in EFL English composition: An exploratory case study. British Journal of Educational Technology, 44(1), 1-4. https://doi.org/10.1111/j.1467-8535.2012.01302.x

MacIntyre, P. D., Dörnyei, Z., Clément, R., \& Noels, K. A. (1998). Conceptualizing willingness to communicate in a L2: A situational model of L2 confidence and affiliation. Modern Language Journal, 82, 545-562. https://

McDonald, E. (2017, April 21). The global games market will reach $\$ 108.9$ billion in 2017, with mobile taking 42\%. Retrieved from https://newzoo.com/in sights/articles/the-global-games-market-will-reach-108-9-billion-in-2017-with-mob ile-taking-42/

McDonough, K., \& Sunitham, W. (2009). Collaborative dialogue between Thai EFL learners during self-access computer activities. TESOL Quarterly, 43, 231254. https://

Newgarden, K., \& Zheng, D. (2016). Recurrent languaging activities in World of Warcraft: Skilled linguistic action meets the Common European Framework of Reference. ReCALL, 28, 274-304. https://doi.org/10.1017/S0958344016000112

Newgarden, K., Zheng, D., \& Liu, M. (2015). An eco-dialogical study of second language learners' World of Warcraft (WoW) gameplay. Language Sciences, 48, 22 24. https://doi.org/10.1016/j.langsci.2014.10.004

Perry, B. (2015). Gamifying French language learning: A case study examining a quest-based, augmented reality mobile learning-tool. Procedia-Social and Behavioral Sciences, 174, 2308-2315. https://

Piirainen-Marsh, A., \& Tainio, L. (2009). Collaborative game-play as a site for participation and situated learning of second language. Scandinavian Journal of Educational Research, 53(2), 167-183. https://doi.org/10.1080/00313830902757584

Purushotma, R. (2005). Commentary: You're not studying, you're just... Language Learning and Technology, 9(1), 80-96.

Purushotma, R., Thorne, S. L., \& Wheatley, J. (2009). 10 key principles for designing video games for foreign language learning. Retrieved from https://lingua 
lgames.wordpress.com/article/10-key-principles-for-designing-video-27mkxqba7b 13d-2/

Rama, P. S., Black, R. W., van Es, E., \& Warschauer, M. (2012). Affordances for second language learning in World of Warcraft. ReCALL, 24, 322-338. https://

Ranalli, J. (2008). Learning English with The Sims: Exploiting authentic computer simulation games for L2 learning. Computer Assisted Language Learning, 21, 441455. https://

Ratner, C. (2002). Cultural psychology: Theory and method. New York, NY: Kluwer/Plenum. https://

Reinders, H., \& Wattana, S. (2014). Can I say something? The effects of digital game play on willingness to communicate. Language Learning and Technology, 18 (2), 101-123.

Reinhardt, J., \& Thorne, S. L. (2016). Metaphors for digital games and language learning. In F. Farr \& L. Murray (Eds.), Routledge handbook of language learning and technology (pp. 415-430). London, England: Routledge.

Riley, T., \& Douglas, S. R. (2016). The multicultural café: Enhancing authentic interaction for adult English language learners through service learning. TESL Canada Journal, 34(1), 25-50. https://doi.org/10.18806/tesl.v34i1.1254

Ryoo, H. K. (2009). Language related episode (LRE) in learner interactions as an opportunity for language learning. English Teaching, 64, 315-335. https://doi. org/10.15858/engtea.64.4.200912.315

Saker, M., \& Frith, J. (2018). Locative media and sociability: Using location-based social networks to coordinate everyday life. Architecture_Media_Politics_Society, 14 (1), 1-21. https://doi.org/10.14324/111.444.amps.2018v14i1.001

Sato, M., \& Viveros, P. (2016). Interaction or collaboration? Group dynamics in the foreign language classroom. In M. Sato \& S. Ballinger (Eds.), Peer interaction and second language learning: Pedagogical potential and research agenda (pp. 91112). Amsterdam, Netherlands: John Benjamins. https://

Scholz, K., \& Schulze, M. (2017). Digital-gaming trajectories and second language development. Language Learning and Technology, 21(1), 100-120.

Schwienhorst, K. (2002). Why virtual, why environments? Implementing virtual reality concepts in computer-assisted language learning. Simulation and Gaming, 33(2), 196-209. https://

Seedhouse, P., Preston, A., Oliver, P., Jackson, D., Heslop, P., Balaam, M., ... Kipling, M. (2014). The European Digital Kitchen Project. Bellaterra Journal of Teaching and Learning Language and Literature, 7, 1-16. https://doi.org/10. $5565 / \mathrm{rev} / \mathrm{jtl} 3.554$

Sert, O., \& Balaman, U. (2018). Orientations to negotiated language and task rules in online L2 interaction. ReCALL, 30, 355-374. https://doi.org/10.1017/ s0958344017000325

Squire, K. D. (2009). Mobile media learning: Multiplicities of place. On the Horizon, 17, 70-80. https://

Storch, N. (2008). Metatalk in a pair work activity: Level of engagement and implications for language development. Language Awareness, 17(2), 95-114. https://

Storch, N., \& Wigglesworth, G. (2010). Learners' processing, uptake and retention of corrective feedback on writing: Case studies. Studies in Second Language Acquisition, 32, 303-334. https://doi.org/10.1017/S0272263109990532

Swain, M. (2000). The output hypothesis and beyond: Mediating acquisition through collaborative dialogue. In J. P. Lantolf (Ed.), Sociocultural theory and second language learning (pp. 97-114). Oxford, England: Oxford University Press. 
Swain, M. (2006). Languaging, agency and collaboration in advanced second language learning. In H. Byrnes (Ed.), Advanced language learning: The contributions of Halliday and Vygotsky (pp. 95-108). London, England: Continuum.

Swain, M., \& Lapkin, S. (1998). Interaction and second language learning: Two adolescent French immersion students working together. Modern Language Journal, 82, 320-337. https://

Swain, M., \& Lapkin, S. (2001). Focus on form through collaborative dialogue: Exploring task effects. In M. Bygate, P. Skehan, \& M. Swain (Eds.), Researching pedagogical tasks: Second language learning, teaching and testing (pp. 99-118). Harlow, England: Longman.

Swain, M., \& Lapkin, S. (2002). Talking it through: Two French immersion learners' response to reformulation. International Journal of Educational Research, 37, 285-304.

Swain, M., \& Watanabe, Y. (2013). Languaging: Collaborative dialogue as a source of second language learning. In C. Chapelle (Ed.), The encyclopedia of applied linguistics (pp. 1-8). Oxford, England: Wiley-Blackwell. https://

Sykes, J., Reinhardt, J., \& Thorne, S. L. (2010). Multiplayer digital games as sites for research and practice. In F. Hult (Ed.), Directions and prospects for educational linguistics (pp. 117-135). New York, NY: Springer.

Tarone, E. (2009). A variationist perspective on the interaction approach. In A. Mackey \& C. Polio (Eds.), Multiple perspectives on interaction: Second language research in honor of Susan M. Gass (pp. 41-57). New York, NY: Routledge.

Thorne, S. L. (2008). Transcultural communication in open Internet environments and massively multiplayer online games. In S. Magnan (Ed.), Mediating discourse online (pp. 305-327). Amsterdam, Netherlands: John Benjamins.

Thorne, S. L. (2010). The "intercultural turn" and language learning in the crucible of new media. In F. Helm \& S. Guth (Eds.), Telecollaboration 2.0 for language and intercultural learning (pp. 139-164). Bern, Switzerland: Peter Lang.

Thorne, S. L. (2012a). Gaming writing: Supervernaculars, stylization, and semiotic remediation. In G. Kessler, A. Oskoz, \& I. Elola (Eds.), Technology across writing contexts and tasks (pp. 297-316). San Marcos, TX: CALICO Monographs.

Thorne, S. L. (2012b). Massively semiotic ecologies and L2 development: Gaming cases and issues. In S. De Wannemacker, S. Vandercruysse, \& G. Clarebout (Eds.), Serious games: The challenge, Vol. CCIS 280 (pp. 18-31). Berlin, Germany: Springer-Verlag.

Thorne, S. L. (2013). Language learning, ecological validity, and innovation under conditions of superdiversity. Bellaterra Journal of Teaching and Learning Language and Literature, 6(2), 1-27. https://doi.org/10.5565/rev/jt13.526

Thorne, S. L., Black, R. W., \& Sykes, J. (2009). Second language use, socialization, and learning in Internet interest communities and online games. Modern Language Journal, 93, 802-821. https://doi.org/10.1111/j.1540-4781.2009.00974.x

Thorne, S. L., \& Hellermann, J. (2015). Sociocultural approaches to expert-novice relationships in second language interaction. In N. Markee (Ed.), Handbook of classroom interaction (pp. 281-298). Oxford, England: Wiley-Blackwell.

Thorne, S. L., \& Hellermann, J. (2017). Mobile augmented reality: Hyper contextualization and situated language usage events. In Proceedings of the XVIII International CALL Conference: CALL in context (pp. 721-730). Retrieved from http://ca 112017.language.berkeley.edu/wp-content/uploads/2017/07/CALL2017çpro ceedings.pdf

Thorne, S. L., Hellermann, J., Jones, A., \& Lester, D. (2015). Interactional practices and artifact orientation in mobile augmented reality game play. Psychology Journal, 13, 259-286. 
Tocaimaza-Hatch, C. C. (2016). Mediated vocabulary in native speaker-learner interactions during an oral portfolio activity. Foreign Language Annals, 49, 336354. https://

van Lier, L. (2004). The ecology and semiotics of language learning: A sociocultural perspective. London, England: Kluwer Academic.

Watanabe, Y., \& Swain, M. (2007). Effects of proficiency differences and patterns of pair interaction on second language learning: Collaborative dialogue between adult ESL learners. Language Teaching Research, 11(2), 121-142. https:/ /

Watanabe, Y., \& Swain, M. (2008). Perception of learner proficiency: Its impact on the interaction between an ESL learner and her higher and lower proficiency partners. Language Awareness, 17, 115-130. https://

Wei, L. (2018). Translanguaging as a practical theory of language. Applied Linguistics, 39, 9-30. https://doi.org/10.1093/applin/amx039

Williams, J. (1999). Learner-generated attention to form. Language Learning, 49, 303-346. https://

Zeng, G., \& Takatsuka, S. (2009). Text-based peer-peer collaborative dialogue in a computer-mediated learning environment in the EFL context. System, 37, 434 446. https://

Zheng, D. (2012). Caring in the dynamics of design and languaging: Exploring second language learning in 3D virtual spaces. Language Sciences, 34, 543-558. https://doi.org/10.1016/j.langsci.2012.03.010

Zheng, D., Liu, Y., Lu, A., Lambert, A., Tomei, D., \& Holden, D. (2018). An ecological community becoming: Language learning as first-order experiencing with place and mobile technologies. Linguistics and Education, 44, 45-57. https://doi.org/10.1016/j.linged.2017.10.004

Zheng, D., Newgarden, K., \& Young, M. F. (2012). Multimodal analysis of language learning in World of Warcraft play: Languaging as values-realizing. ReCALL, 24, 339-360. https://doi.org/10.1017/S0958344012000183

Zheng, D., Schmidt, M., Hu, Y., Liu, M., \& Hsu, J. (2017). Eco-dialogical learning and translanguaging in open-ended 3D virtual learning environments: Where place, time, and objects matter. Australasian Journal of Educational Technology, 33(5), 107-122. https://doi.org/10.14742/ajet.2909

Zuengler, J., \& Bent, B. (1991). Relative knowledge of content domain: An influence on native-nonnative conversations. Applied Linguistics, 12, 397-415. https://doi.org/10.1093/applin/12.4.397

\section{Supporting Information}

Additional Supporting Information may be found in the online version of this article:

\section{Appendix A. Intervention Procedures}

